\title{
IEA EBC Annex 67 Energy Flexible Buildings
}

Søren Østergaard Jensen ${ }^{\mathrm{a}}$, Anna Marszal-Pomianowska ${ }^{\mathrm{b}}$, Roberto Lollini ${ }^{\mathrm{c}}$, Wilmer Pasut ${ }^{\mathrm{c}}$, Armin Knotzer ${ }^{\mathrm{d}}$, Peter Engelmann ${ }^{\mathrm{e}}$, Anne Stafford ${ }^{\mathrm{f}}$, Glenn Reynders ${ }^{\mathrm{g}}$

5 a Danish Technological Institute, Gregersensvej 2, DK-2630 Taastrup, Denmark. sdj@teknologisk.dk

${ }^{\mathrm{b}}$ Department of Civil Engineering, Aalborg University, Sofindelsvej 9-11, DK-9000, Aalborg, Denmark. ajm@civil.aau.dk

${ }^{c}$ EURAC research Institute for Renewable Energy, Via G. Di Vittorio 16, I-39100 Bolzano, Italy. roberto.lollini@eurac.edu,wilmer.pasut@eurac.edu

10 d AEE - Institut für Nachhaltige Technologien, Feldgasse 19, A-8200 Gleisdorf, Austria. a.knotzer@ aee.at Fraunhofer Institute for Solar Energy Systems, ISE, Department Energy Efficient Buildings, Heidenhofstrasse 2, 79110 Freiburg, Germany, Peter.Engelmann@ise.fraunhofer.de

f Leeds Sustainability Institute, Leeds Beckett University, BPA223 Broadcasting Place, City Campus, Leeds LS2 9EN, UK. a.stafford@leedsbeckett.ac.uk

15 g Department of Civil Engineering, KU Leuven, Kasteelpark Arenberg 40, B-3001 Heverlee, Belgium. glenn.reynders@kuleuven.be

\section{Abstract}

The increasing global energy demand, the foreseen reduction of available fossil fuels and the increasing evidence

off global warming during the last decades have generated a high interest in renewable energy sources. However, renewable energy sources, such as wind and solar power, have an intrinsic variability that can seriously affect the stability of the energy system if they account for a high percentage of the total generation.

The Energy Flexibility of buildings is commonly suggested as part of the solution to alleviate some of the upcoming challenges in the future demand-respond energy systems (electrical, district heating and gas grids). Buildings can supply flexibility services in different ways, e.g. utilization of thermal mass, adjustability of HVAC system use (e.g. heating/cooling/ventilation), charging of electric vehicles, and shifting of plug-loads. However, there is currently no overview or insight into how much Energy Flexibility different building may be able to offer to the future energy systems in the sense of avoiding excess energy production, increase the stability of the energy networks, minimize congestion problems, enhance the efficiency and cost effectiveness of the future energy networks. Therefore, there is a need for increasing knowledge on and demonstration of the Energy Flexibility buildings can provide to energy networks. At the same time, there is a need for identifying critical aspects and possible solutions to manage this Energy Flexibility, while maintaining the comfort of the occupants and minimizing the use of non-renewable energy.

In this context, the IEA (International Energy Agency) EBC (Energy in Buildings and Communities program)

Annex 67: "Energy Flexible Buildings" was started in 2015. The article presents the background and the work plan of IEA EBC Annex 67 as well as already obtained results.

Annex 67 is a corporation between participants from 16 countries: Austria, Belgium, Canada, China, Denmark, Finland, France, Germany, Ireland, Italy, The Netherlands, Norway, Portugal, Spain, Switzerland and UK. 


\section{Keywords}

40 Energy Flexible Buildings; Smart Energy Networks; Demand Side Management; Load Control, Demand Response; Flexibility Indicators 


\section{Introduction}

The increasing global energy demand, the foreseen reduction of available fossil fuels and the increasing evidence off global warming during the last decades have generated a high interest in renewable energy sources. The penetration of renewable energy sources (RES) is increasing rapidly worldwide, with a $26 \%$ increase of installed photovoltaic capacity to $177 \mathrm{GW}$ and a $16 \%$ increase of wind capacity to $370 \mathrm{GW}$ from 2013 to 2014 [1] [2]. This trend is expected to continue as several countries already have highly ambitious targets. The Renewable Energy Directive requires that by 2020 at least $20 \%$ of EU's total energy demand comes from renewables [3], while Germany has a goal of at least $80 \%$ of the gross electricity consumption coming from renewable energy by 2050 [4]. Some countries have even set RES targets as high as $100 \%$ of the total energy mix, including Denmark which plans to cover $100 \%$ of the energy demand with renewables by 2050 [5].

However, energy sources, such as wind and solar power, have an intrinsic variability that can seriously affect the stability of the energy system, if they account for a high percentage of the total generation. In order to accommodate a high penetration of variable renewable energy sources in future a transition from generation on demand to consumption on demand is often suggested. In practice, this will mean that the energy consumption needs to become flexible.

At the same time, the ambition towards net zero energy buildings (NZEB) imposes new challenges as buildings no longer only consume, but also generate heat and power locally - commonly called prosumers. Consequently, the grid must be designed with respect to the energy demand (both heat and electricity) as well as the local energy generation. Simplified calculation tools for local demand and generation help to assess the netload profile of NZEB [6], [7]. If not considered, it may result in limitations of the amount of exported energy for building owners to avoid power quality problems; e.g. Germany has already enforced restrictions on private PV generation exported to the grid [8]. Furthermore, today the distribution grid is often dimensioned based on buildings heated by sources other than electricity, e.g. oil or gas burners. However, the transition to a renewable energy system will in many areas lead to an increase in electrical heating, e.g. by heat pumps, even if the foreseen reduction in the space heating demand via energy renovation is realized. The expected penetration of electrical vehicles may further increase the loads in the distributed grids, but they may also be used for peak shaving by using their batteries [9]. All these factors will in many distribution grids call for major reinforcement of the existing grids or a more intelligent way of consuming electricity in order to avoid congestion problems. The latter is called Smart Grids (or Smart Energy Networks, when energy carriers other than electricity are considered as well) where both demand and local production in the distribution networks are controlled to stabilize the energy 
networks. Buildings are expected to have an important role in future Smart Grids/Energy networks [10], 11], [12], [13]. The proposal of a Smartness Indicator in the upcoming revision of the EPBD [14] should be seen in this

light. The purpose of the Smartness Indicator in EPBD is to "inform the consumers about the ability of buildings to operate more efficiently, monitor and control energy use and interact with the users and the grid" [15]. Furthermore, it is stated that "A Smartness indicator will reflect the ... (iii) readiness of the building to participate in demand response, charge electric vehicles and host energy storage systems" [15].

In most developed countries, the energy use in buildings accounts for $30-40 \%$ of the total energy consumption [16] and it is used for space heating, heating of domestic hot water, cooling, ventilation, pumps, control and lighting of rooms as well as for appliances used by occupants. A large part of the energy demand of buildings may be shifted in time [17], [18], [19], and it may thus significantly contribute to increasing flexibility of the demand in the energy system. In particular, the thermal part of the energy demand, e.g. space heating/cooling, ventilation (ventilation is both at thermal and electrical load), domestic hot water as well as hot water for washing machines, dishwashers and heat for tumble dryers, can be shifted. Care should, however, be taken when obtaining Energy Flexibility from buildings in order not to jeopardize the comfort of the occupants. Ventilation is e.g. important for health and pollutant control.

All buildings have thermal mass embedded in their constructions, which makes it possible to store a certain amount of heat (or cold in case of air-conditioned buildings) [20], [21], [22]. Depending on the amount, distribution, speed of charging/discharging, etc. of the thermal mass, it is possible to postpone heating or cooling for a certain period of time without jeopardizing the thermal comfort in the building. Moreover, if a building is excess pre-heated/cooled within the comfort range of the room temperature (i.e. heated to the upper comfort limit or cooled to the lower comfort limit) prior to a shutdown of heating/cooling, it is possible to prolong the shutdown period. The time constant of buildings varies - depending on the amount and exploitability of the thermal mass together with the heat loss, internal gains, user pattern and the actual climate conditions - typically between a few hours to several days. Many buildings may also contain different kinds of discrete storages (e.g. domestic hot water tanks, buffer tanks using both water and PCM (Phase Change Materials) and storage heaters, but also batteries, e.g. in connection with PV systems or electric vehicles) that may add to the flexibility of the energy demand of the buildings. One such typical storage is the domestic hot water tank, which might be excess preheated before a low energy level situation. In general water tanks are better suited to provide short-term flexibility, whereas PCM tanks and TCM (Thermo Chemical Material) tanks can show an advantage in offering long-term 
flexibility [23]. The excess heat may be utilized for space heating, but may also be used for white goods such as hot-fill dishwashers, washing machines, and tumble dryers in order to decrease and shift their electricity need.

A Danish study [24] on large-scale implementation of heat pumps in individual homes outside areas with district heating showed an increased utilization of excess power generation from wind turbines and a reduced use of fuels during periods with low electricity production by utilizing storage, e.g. in the building constructions or in water tanks. The study showed that excess RES production could be reduced by up to $20 \%$ - excess power that otherwise would be wasted or sold at a low or even negative price. In the study, the most cost-effective solution was utilization of the thermal mass of buildings as heat storage, even if only a small part of the total thermal capacity can be exploited by existing technologies. A similar approach may be used in communities with district heating or community heating (common heating system for a limited number of buildings). Excess renewable energy generation, (e.g. wind power) may be utilized for heating in the district/community heating plant. However, to be able to store sufficient heat the thermal mass of the buildings connected to the district/community heating grid may be utilized in the same way as in buildings with heat pumps.

Figure 1 shows an example of how the flexibility of houses with heat pumps may decrease the need for reinforcement of the local $0.4 \mathrm{kV}$, where the houses are situated [25]. Figure 1 shows a winter situation for a small Danish feeder with only single family houses.

$\mathbf{a}$

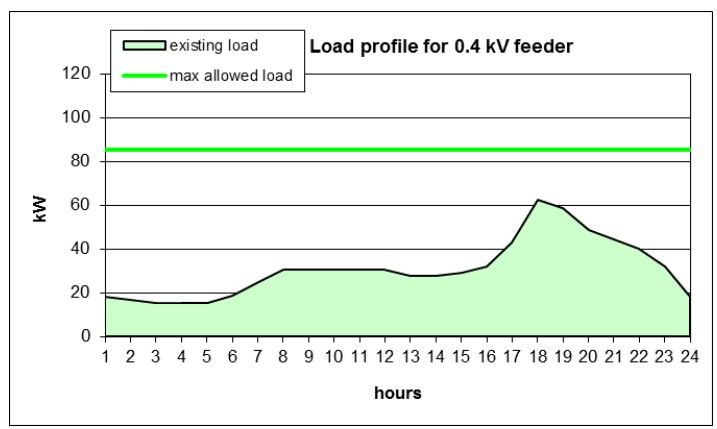

b

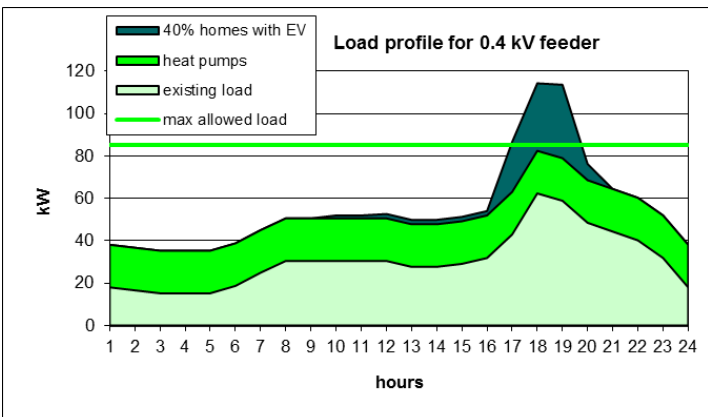




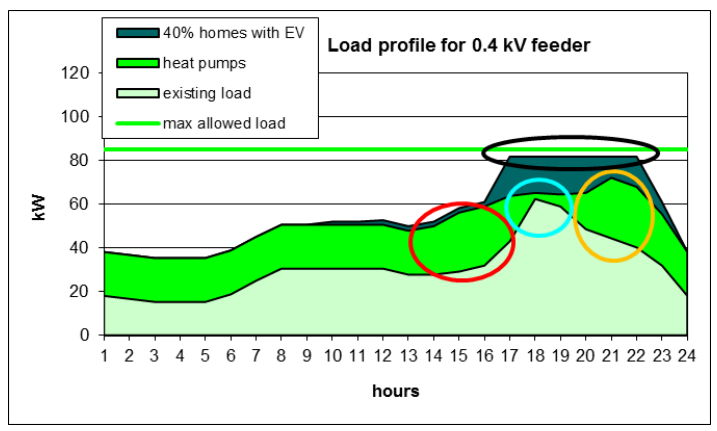

Fig. 1. The graphs show an example of the introduction of heat pumps and electrical vehicles in a $0.4 \mathrm{kV}$ outlet/feeder [16]:

a) the existing situation. The peak from 17:00 to 20:00 is called the cooking peak due to people coming home from work and start cooking. The peak also is due to swithching on other applieaancies.

b) business as usual: heat pumps and electrical vehicles (EVs) in the system will demand a reinforcement of the grid as the demand exceeds the max allowed load

c) a Smart Grid solution where the buildings prior to the cooking peak (17:00-20:00) are excess heated within the comfort band of the room temperature (red circle). The buildings are mainly free floating during the cooking peak (blue circle) but need extra heat after the cooking peak (orange circle). The charging of the EV's is controlled intelligently in order to keep the demand below the max allowed load (black circle).

Although various investigations of buildings in the Smart Grid context have been carried out, research on how Energy Flexibility in buildings can help stabilize the future energy system and thereby facilitate large penetration of renewable energy sources, is still in its early stages. The investigations have either focused on how to control a single component - often simple on/off controlled (e.g. [26], [27]) - or based on simulations focused on defining indicators for Energy Flexibility (e.g. [28]), rather than on how to optimize the Energy Flexibility of the buildings themselves.

Although the concept of load flexibility is not new, there is currently no overview or insight into how much Energy Flexibility different types of building and their usage may be able to offer to the future energy systems. This is the reason why IEA EBC Annex 67 Energy Flexible Buildings was initiated.

\section{IEA EBC Annex 67 Energy Flexible Buildings}

The aim of IEA EBC Annex 67 is to increase knowledge, and to identify critical aspects and possible solutions concerning the Energy Flexibility provided by buildings, as well as the means to exploit and control this flexibility [29]. This knowledge is important in order to be able to incorporate the Energy Flexibility of buildings in future energy systems and thereby increase the uptake of renewable energy sources. The obtained knowledge is also important when developing business cases for the utilization of building Energy Flexibility in future energy systems.

\subsection{Objectives}

To fulfil the aims of IEA EBC Annex 67 and to facilitate future Energy Flexible buildings IEA EBC Annex 67 focuses on the following specific objectives: 
- Development of a common terminology and definition of "Energy Flexibility in buildings" together with a classification method

- Investigation of user comfort, motivation and acceptance associated with the introduction of Energy Flexibility measures in buildings

- Investigation of the Energy Flexibility potential in different buildings and contexts, and development of modelling approaches and control strategies

- Investigation of the aggregated Energy Flexibility of clusters of buildings and the potential effect on the match between energy demand and production by RES

- Demonstration of Energy Flexibility in buildings through experimental and field studies

\subsection{Scope and Demarcation}

IEA EBC Annex 67 focuses on analysing the potential Energy Flexibility in buildings and on how to control this flexibility without loss of comfort for the users in the buildings. Thereby, thermal building technologies such as thermal storage in building constructions and water tanks and the control of HVAC systems (e.g. heat pumps, air conditioning and ventilation) are the main focus of IEA EBC Annex 67. Additionally, the interaction between the building load, the on-side energy production (based on renewable energy) and electrical loads (e.g. lighting) as well as storage in batteries are also part of the work of IEA EBC Annex 67.

IEA EBC Annex 67 addresses both residential and non-residential buildings. However, these two sectors are treated separately because the challenges and possible solutions differ for the two sectors. IEA EBC Annex 67 addresses both new constructions and renovated buildings. Renovation of buildings is of special importance because the majority (75\%) of buildings existing today will still be there in 2050 . From a cost point of view Energy Flexibility should be considered as a part of a renovation process as it is cheaper to introduce Energy Flexibility during a renovation when constructions and systems may be changes or modified anyway.

IEA EBC Annex 67 focuses on both single buildings and clusters of buildings as the surrounding energy networks are influenced by the individual buildings, but it is their total energy demand, which is detected within the same distribution network. Furthermore, the Energy Flexibility of a single building is typically too small to be bid into a flexibility market. It is, therefore, also important to investigate the aggregated flexibility given by pooling of several buildings.

\subsection{Organization of IEA EBC Annex 67}

IEA EBC Annex 67 is organized into three subtasks: 
Subtask A: Definitions and Context dealing with the development of a common terminology and definition of Energy Flexibility in buildings, the development of key performance indicators for the characterization of Energy Flexible buildings (both for single buildings and for clusters of buildings at an aggregated level), and the investigation of barriers and motivations for stakeholders including possible business cases for commercial utilization of Energy Flexibility of buildings.

Subtask B: Analysis, Development and Testing dealing with the investigation of the potential Energy Flexibility in buildings using different simulation tools, the development of control strategies for the optimization of the possible Energy Flexibility in buildings and test of systems and control strategies in test facilities

Subtask C: Demonstration and User Perspectives dealing with the obtainable Energy Flexibility in real buildings and clusters of buildings including the investigation of the barriers and motivations for the stakeholders involved.

\section{Completed and ongoing work}

As IEA EBC Annex 67 will run until the end of June 2019, only a few results of the work have been finalized or published by now. The present chapter describes the already obtained results, but focuses mainly on the planned and ongoing work. The article describes the status of IEA EBC Annex 67 as of the end of April 2017.

The aim of IEA EBC Annex 67 is to create common knowledge of design, implementation, use, and evaluation of Energy Flexibility in single buildings and clusters of buildings.

\subsection{Definition and Context - Subtask A}

The concept of load flexibility by energy storage is not new, but as the concept of Energy Flexibility in buildings is a relatively new research area, there is a need for the development of a framework and common terminology. On the one hand the terminology should be easily understood by the building community, which should provide the Energy Flexibility. On the other hand, it should also allow the energy network side to understand how Energy Flexibility of buildings can be an active element of future energy networks. For the latter, there is a need for applicable flexibility indicators and coherent quantification methods, which characterize the buildings in such a way that it is possible to determine the role of Energy Flexible buildings or clusters of buildings in future flexibility services to the energy networks. Literature reviews on existing concepts and new findings from IEA EBC Annex 67 are the basis of the development of a common definition and terminology for 
Energy Flexibility in buildings. A first literature review on existing methodologies for the quantification of Energy Flexibility in buildings was presented at the international Solar Heating and Cooling SHC 2015 conference [30]. The work underlined the fact that methods aiming at assessing the Energy Flexibility of buildings are diverse, but their implementation can help matching the energy demand to renewable energy capacities. This literature review was extended and the identified flexibility indicators were tested and compared in a single building case study [31]. [31] showed that although the quantification methodologies identified in different studies all have different focuses, three general properties of energy flexibility emerge:

i) the time over which energy and power can be shifted or shedded;

ii) the amount of energy or power that can be shifted or shedded;

iii) the associated cost or efficiency loss at the building level that results from activating this flexibility.

The application of flexibility may have different goals occurring at the same time that need to be weighted in a transparent way. It has been proposed to work on a weighting system to be applied to the flexibility indicators to give them higher or lower importance depending on the goal of flexibility.

Starting from the literature reviews, a definition, and a terminology are being developed. The present IEA EBC Annex 67 working definition of Energy Flexibility in buildings is:

The Energy Flexibility of a building is the ability to manage its demand and generation according to local climate conditions, user needs, and energy network requirements.

Energy Flexibility of buildings will thus allow for demand side management/load control and thereby demand response based on the requirements of the surrounding energy networks.

The definition of Energy Flexibility is important for defining metrics and methodologies for the characterization of Energy Flexibility in buildings. In order to develop the methodologies, investigate the view of stakeholders and possible business cases the work is divided into six main activities:

\section{Energy Flexibility Indicators for single buildings}

There are mainly two different kinds of indicators quantifying Energy Flexibility and the impact that technologies, components or control strategies have on the available flexibility. Some indicators purely depend on the physical/technological properties of the building, describing the amount (or potential amount) of energy or power that can be shifted ("potential indicators"). The second group of indicators is dependent on the specific application, subordinated to the scope and target for which energy flexibility is being applied ("performance indicators"). For example, the technical storage potential of a building will not change, but the storage performance will change whether the goal of control is $\mathrm{CO}_{2}$-emission reduction or peak power reduction. For 
this reason, a weighting method, which combines "potential indicators" with a set of transparent (for easy interpretation) weighting factors depending on the actual business case, is being investigated. As such, IEA EBC Annex 67 aims at linking "potential" and "performance" indicators in a transparent manner to increase the comparability of results among studies on the energy flexibility of single buildings.

\section{Energy Flexibility Indicators for clusters of buildings}

Energy flexibility can be provided at the level of single buildings or cluster of buildings. However, before identifying indicators to assess the flexibility of a cluster of buildings, it is important to define what a cluster of buildings is from the prospective of Energy Flexibility. A first definition (which is still under review) is:

A cluster of buildings is a group of buildings physically connected or commercially aggregated.

Commercially aggregated means that the buildings are not necessarily connected to the same distributed energy networks. An example of commercial aggregation is the case of different buildings with the same owner located at different parts of the distribution grid. In this case, the owner can negotiate a better tariff with the grid authority in exchange for a temporary reduction/increase of the energy consumption by the building cluster when this is needed by the grid.

A literature review on Key Performance Indicators (KPIs) on clusters of buildings has been carried out

\section{Methodology for characterization of energy flexibility in buildings}

Based on the identification of Energy Flexibility indicators for single buildings and clusters of buildings together with the simulation of Energy Flexibility in Subtask B (section 3.2), a methodology for the characterization of Energy Flexibility in buildings will be developed. A review of previous projects in which energy flexibility-related indicators have been used to drive the design process has been carried out. The outcomes of this activity, together with the indicators presented before, will shape the methodology to characterize energy flexibility in buildings.

\section{Labelling of energy flexibility in buildings}

The EU commission is aiming at introducing a Smartness Indicator in EPBD [15]. It will rate the readiness of a building to adapt its operation to the needs of the occupants and of the grid, and to improve its performance; the determination and calculation of the smartness indicator will focus on the capability of the building's realtime flexibility and remote controllability. As the cost of assessing the Smartness Indicator of a building must be low - $€ 15$ for residential and $€ 100$ for non-residential buildings - as defined by the EU Commission in [15] - the proposed Smartness Indicator has to be very simple, and most possibly too simple for characterizing the obtainable Energy Flexibility. A dialogue between the study "Support for setting up a Smart Readiness Indicator 
for Buildings and related impact assessment" (CALL FOR TENDERS ENER/C3/2016-554) and IEA EBC Annex 67 has been established. IEA EBC Annex 67 has offered to support the EU study. However, it is foreseen that the IEA EBC Annex 67 proposals for labelling will be different from the EPBD Smartness Indicators due to the large complexity of the Energy Flexibility in buildings.

There are not only technical and formal aspects that need to be clarified and investigated to foster a robust implementation of energy flexibility in future buildings. It is of paramount importance to study the impact, that Energy Flexibility has on building users and the motivation for its application. Furthermore, the economical convenience and feasibility of the proposed technology or control strategies must be clarified. Two activities in Subtask A focus on these key aspects:

\section{User needs, motivation and barriers for application of Energy Flexibility in buildings}

Energy Flexibility may have a direct impact on the daily life and economy of the stakeholders (users, owners, caretakers, facility managers, etc.). A successful implementation of energy flexibility strategies, and the extent of this implementation, strongly depends on the acceptance and motivation of the stakeholders. A first literature review concentrating particularly on shopping centres has been conducted. The aim is to extend this literature review to other building categories, e.g. residential and office buildings. The literature review will be extended by surveys conducted in IEA EBC Annex 67 - see later in the article.

\section{Aggregation potential related to business models}

Beside some exceptions in which the amount of energy that can be shifted is considerable, the available Energy Flexibility in a building is often very small, - too small to be traded on a flexibility market. Large commercial buildings may be able to trade directly on a flexibility market, but for smaller buildings there is a need for aggregators that pool the small amounts of Energy Flexibility from many buildings in order to be able to bit in with a large amount of flexibility on the market. It is investigated how the flexibility can be "sold" to existing markets or which new markets should be designed.

The aggregation potential is mainly dependent on the market framed by different business models. IEA EBC Annex 67 investigates the energy flexibility potential for energy service aggregators and the different possible business models. This is being done for the power market, with the aim of including business models for district heating as well. Robust and reliable business models for building energy flexibility (e.g. for bundling buildings, photovoltaic, electric vehicle, and electricity supply) are important for possible new actors working in the Energy Flexible building chain. 
Energy Flexibility in buildings is a complex topic (as seen in figure 2) where the available Energy Flexibility is strongly dependent on the design of the building, the installed energy service systems and the control of the energy demand in the building. Furthermore, the actual obtainable Energy Flexibility is highly dependent on the use of the building, including user behaviour and often the climate, which the buildings are exposed to, as well as the needs of the surrounding energy networks.

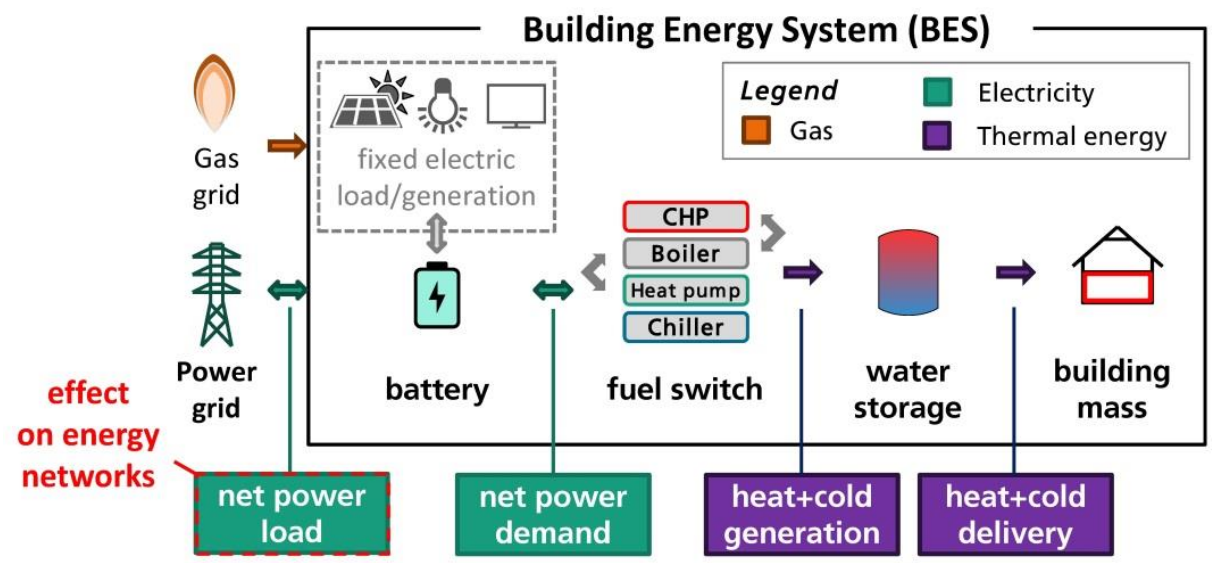

Fig. 2. Schematic of a building energy system highlighting the different stages where demand and delivery can be decoupled or heat/cold generators can be switched for a specific amount of time, thus providing Energy Flexibility [32].

- Batteries can create a time shift between the net power load and the net power demand of the building.

- Fuel switch involves a change in the sequencing of different heat and cold generators in order to alter the relation between power demand and generation of heating and cooling power, based on a grid signal. Technically, it relies on a variation of the end energy form which is used to provide thermal energy to the building. This may effectively cause an energy storage process at a higher energy system level, e.g. in the gas grid.

- Water tanks can introduce a time shift between heat generation and heat delivery.

- The thermal building mass can be used for thermal storage by modifying the heat delivery trajectory [32].

On one hand, the focus of Subtask B is the theoretical exploration and assessment of the flexibility potential, going from components (heat pumps, chillers, CHP or other appliances) to single buildings and up to the aggregated level with clusters of buildings. On the other hand, different configurations of building characteristics, energy service systems, energy network's needs, and user behaviour will be tested in simulation models as well as in realistic yet controlled environments (lab tests, typically as hardware-in-the-loop tests). Using simulations and experiments, Subtask B hence explores the relation between the "potential indicators" and the "performance indicators" for energy flexibility as defined in subtask A. The objective is to explore and assess the availability of energy flexibility and provide documentation on different strategies of this concept.

\section{Modelling and Simulation}

Not only different strategies for incorporating Energy Flexibility in the operation of buildings is modelled and analysed, but the comparability of different technologies and approaches is also addressed.

An important challenge is the harmonization of input parameters for simulation studies. As the influence of boundary conditions (weather) and user behaviour on Energy Flexibility is dominant [33], a "simulation test bed" is proposed: using identical or harmonized boundary conditions for as many input parameters as possible 
and clear documentation of specific parameters when non-standardized inputs are used to facilitate comparability between models and results (figure 3). Therefore, either reference profiles are provided (e.g. a mixture of the electric grid, related $\mathrm{CO}_{2}$ emissions, and energy prices, results from the EU Horizon 2020 project "Market4RES"[34]) or in case specific boundary conditions are used: these datasets are clearly documented and categorized, e.g. by providing typical indicators like heating/cooling degree hours for weather data. Minimum requirements on system models are defined (minimal time step, specific outputs, etc.) but also specific parameters (type and geometry of building, HVAC system, storage (thermal or electrical)) for individual system. These parameters are collected and documented to be able to conduct cross-comparisons between similar systems and approaches, e.g. different target functions, as the goals of the simulations studies (optimization of cost, energy demand reduction or $\mathrm{CO} 2$ emissions) might be different. The different modelling approaches and strategies for Energy Flexibility in buildings (or clusters of buildings) are conducted in an ongoing internal questionnaire.

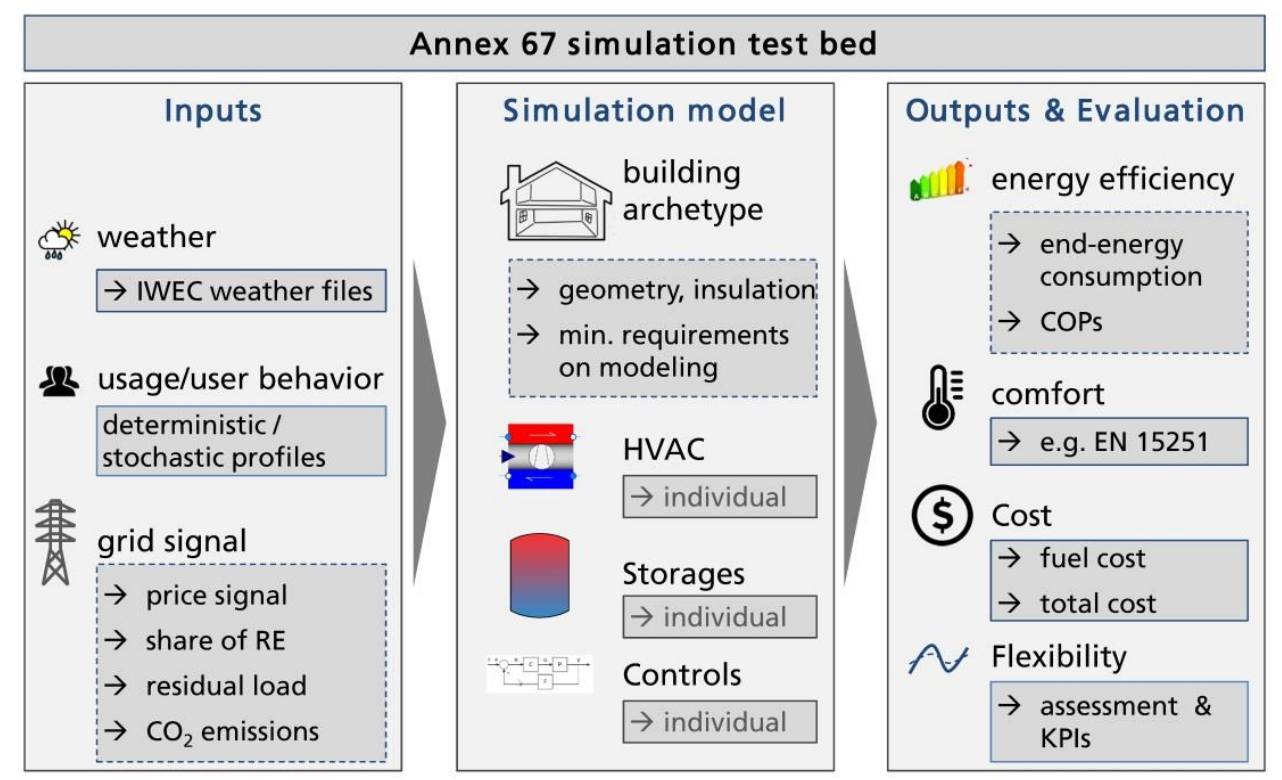

Fig 3: Sketch of the simulation test bed proposed for modelling work in Annex67.

To get a first impression of the needs of the grids, the residual loads in 14 countries and one region in 2030 were simulated based on official plans for the energy demands and utilization of renewable energy resources in 2030 [35]. The residual load is here defined as the load that still has to be covered by fossil fuels. Figure 4 shows the aggregated daily profiles of the residual load for the 14 countries and one region for the months January, April, July and October, 2030. 

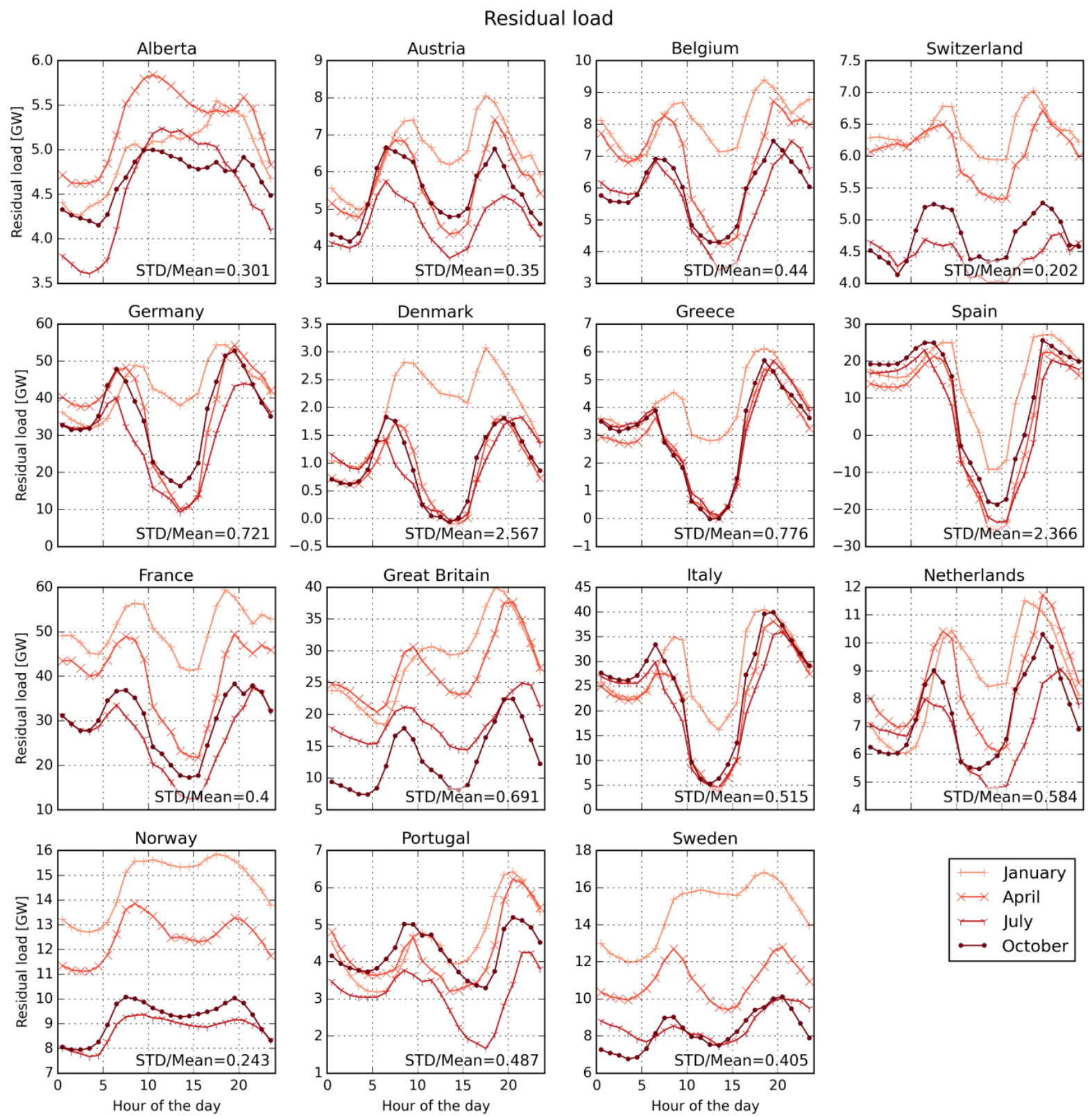

Fig. 4: Aggregated daily profiles of the predicted residual load 2030 for the months January, April, July and October [35]. Please notice different scales on the Y-axis.

In most countries/region, the residual load shows its lowest values around noon as a consequence of peak solar and (on average) wind generation, as well as lower loads during the nights. Even in the aggregated form shown in figure 4, residual loads close or below zero occur in Spain, Denmark, Greece and Italy. This means that especially during sunny and/or windy days, extreme surpluses of renewable electricity (emission-free and at zero marginal cost) are expected. Storing this surplus or making it useful via demand response will be a major challenge and builds a strong case for considering variable grid conditions, e.g. in heat pump and chiller control strategies. 
The analysis of control strategies for the energy-flexible operation of buildings has started with a literature review on existing control strategies [36]. The main conclusion is that multiple specific energy flexibility KPIs exist, which allow for the quantification of different aspects of Energy Flexibility. Most of them are based on rule based control (RBC), while optimal control (OC) and model-predictive control (MPC) can consider different "objective functions", which optimize the system behaviour by taking Energy Flexibility into account. Moreover, they can be assessed with a broader variety of KPIs beyond the sole objective, which they focus on.

The comparison and assessment of control strategies will be continued with the aim of providing an overview of work that has been done in this field with the attempt to categorise different strategies in terms of the utilisation of technical solutions (e.g. thermal storage in the form of water, PCM or building mass, the most common control methods (RBC, OC and/or MPC), and the different methods of incorporation of (external) energy network-parameters (demand side management with direct control of appliances or indirect control using e.g. price signals).

\section{Lab tests}

Simulations are a typical tool to test different control strategies, even some of which may not be realistic or hard to implement in the real world. Control strategies and the combination of hardware components are, therefore, also tested in test facilities under controllable, yet realistic, conditions. Hardware-in-the-loop is utilized, e.g where. a heat pump and other components are tested combined with the energy demand of virtual buildings and exposed to virtual weather and energy network conditions. Here the basic goal is to test and verify the flexibility capacities and control strategies of different systems, as well as to compare this with the findings from the simulation studies.

Tests with different technology (heat pumps, storage systems, etc.) and different control strategies will be carried out in Spain (IREC), Finland (VTT), Germany (Fraunhofer ISE), Denmark (DTI), Norway (NTNU) and Italy (EURAC). The first tests with control strategies tested in a simulation environment are in the preparation phase (definition of software interfaces and dimensioning of hardware) or already being carried out. Tests will be conducted during the next two years.

\subsection{Demonstration and User Perspectives - Subtask C}

Simulation and testing in test facilities are unique tools when trying to understand Energy Flexibility and to develop how Energy Flexibility in buildings may be controlled and offered as support for the surrounding energy networks. However, the ultimate proof is when the systems and control strategies are integrated in real buildings. 
Real buildings are, therefore, studied in detail in case studies to investigate the possible Energy Flexibility in the real world.

When utilizing Energy Flexibility in buildings the comfort and economy of the buildings are influenced. Therefore, there must be careful consideration of the limits or constraints, which should be applied to ensure acceptability to occupants and owners. For this reason, it is also very important to investigate and understand which barriers exist from the point of view of the stakeholders of buildings and how the stakeholders may be motivated to allow their buildings to contribute their Energy Flexibility to stabilize the future energy networks

Therefore, IEA EBC Annex 67 Sub Task C includes demonstration of energy flexibility via case studies (including sharing of data with other subtasks when appropriate and possible), the development of monitoring guidelines associated with energy flexibility, and the investigation of the barriers and motivations associated with stakeholders in real buildings.

The demonstration of different aspects of energy flexibility in various types of real buildings is an important method of validating and testing some of the concepts developed in IEA EBC Annex 67. For example, real datasets acquired from real building operation may be fed in to the simulation studies, and data from real buildings may also be used to inform the development of appropriate control strategies and algorithms. In some cases, the buildings under study may act as a test-bed for the control strategies and algorithms post-development, though this is not likely to occur until near the end of the working phase of IEA EBC Annex 67. Lessons from case studies in real buildings may also help to inform any recommendations on labelling, which is a part of IEA EBC Annex 67 Subtask A. Finally, the case studies allow for the investigation of barriers and motivations of stakeholders in real scenarios.

There are currently nine Case Studies of varying types and scales contributing to IEA EBC Annex 67, ranging from small investigations into domestic hybrid heat pump systems, to studies in office buildings or large-scale assessments of changes to university estates. In the following the case studies are briefly described, and any results already obtained are indicated.

\section{Case Studies}

\section{TU Delft Campus (Netherlands)}

Due to projected changes in the local heat grid, the individual buildings on the TU Delft campus will need to be able to manage their energy demand more effectively taking the new grid requirements as well as the local climate conditions and user needs for indoor comfort into account, when general building supply temperatures for heating are reduced. The transition from a high to a medium supply temperature has far reaching 
consequences on the facility management of the buildings and the redevelopment of the heat grid. Comfort simulations are used to project the required changes on the building level. This case study particularly analyses the barriers and motivations of stakeholders for introducing energy flexibility in the buildings due to changing grid requirements.

\section{Leeds Beckett University (UK)}

Leeds Beckett University estates are undergoing a systematic programme of upgrading. In this case study, two contrasting buildings are modelled - one older mixed-use building, which is due for renovation, and one newer building with more detailed control systems and monitoring. The models are validated using real consumption data, and can subsequently be used to investigate different control scenarios. When possible, the results of the scenario modelling will be used to inform trials of different simple control strategies, for example scheduled shut-down of HVAC systems during certain periods of the day.

\section{Hybrid Heat Pumps in Gas-Connected Dwellings (UK)}

This is a small-scale exploratory study based on in-situ data from two domestic hybrid heat-pump/gasboiler systems installed in the UK. Issues relating to the switching of load from the heat pump to the gas boiler element in response to electrical grid requirements are considered [37]. Results show that, in principle, a switch from heat pump to gas boiler for a period of around one hour at peak times is feasible under certain circumstances.

\section{Heat Pump Hub (Denmark)}

The HP-Hub will contain information about the actual installed heat pump (from the supplier/installer), information about the house (from the Danish Building Register), measurements from the billing meter and possible measurements from the heat pump itself [38]. With the permission of the heat pump owner, aggregators can retrieve data from the HP-Hub in order to determine if a particular heat pump is suitable for providing energy flexibility and could therefore form part of the portfolio of the aggregator. The aggregator may then make an offer to the owner of the heat pump. In this way, the HP-Hub has the potential to facilitate the introduction of energy flexibility services arising from residential heat pumps.

Green Tech Centre (Denmark)

A full model has been developed in Energy Plus for the Green Tech House, a $4000 \mathrm{~m}^{2}$ experimental office building [39]. Strategies to exploit energy flexibility will be based around the control of ventilation or global temperature readjustments. In the case of ventilation, the load can be shifted (pre-ventilation or postponed ventilation), or alternatively ventilation can be reduced during periods of low occupancy. The heating load may 
also be shifted via pre-heating, utilising the thermal mass of the building, and passive heating and cooling can be optimised as far as possible. Although the system is constrained by the legal requirements for thermal comfort and by pre-set $\mathrm{CO}_{2}$ limits, there is a risk of temporarily reduced occupant comfort and/or indoor air quality. Preliminary results show that a rebound effect can take place after the ventilation has been withdrawn for a time. The building operating system is controlled directly by an aggregator system using a number of different algorithm types.

\section{University of Southern Denmark (Denmark)}

This case study considers a university teaching/office building built according to the Danish BR2015 building code. The strategies for exploiting energy flexibility are similar to those described above for the Green Tech Centre, but in addition there is the potential for lighting control via dimming at peak periods. The control is by means of a multi-objective MPC system, and the delivered thermal comfort will be constrained so that it remains within the PMV (Predicted Mean Vote) range of -1 to +1 .

\section{Solar XXI Building (Portugal)}

A low-energy university building at LNEG campus, Lisbon, incorporating BIPV with heat recovery and ground cooling will be studied. The building is currently subject to ongoing monitoring for both energy load and energy generation on a monthly basis, but in order to assess the energy flexibility potential, measurements at a more disaggregated level with a 15-minute resolution have also been made. The latter were collected for one winter (heating season) week and one summer (cooling season) week. Thus, daily load patterns can be analysed and compared with expected generation.

\section{Passivehouse+ Renovation (Austria)}

This project is focussed on the monitoring of NZEB and plus-energy buildings, including one NZEB hotel building, one passivehouse large-volume residential building, and one off-grid building. The monitoring data will be the basis for an optimization of the energy flexibility in the operation of these buildings. Researchers hope to have access to a new demonstration building as well in the latter stages of IEA EBC Annex 67, where lessons learned from the monitoring and optimization activities can be applied with respect to energy flexible operation.

\section{Kropman Breda Building, Eindhoven (Netherlands)}

In this case study, the performance of a medium-sized office building in the Netherlands is explored under demand-side flexibility interventions, which are implemented while keeping comfort parameters within welldefined standard boundaries. The initial intervention strategies included changes in the air supply fan setting and 
in the cooling temperature set-point. The responses of the building and its occupants are evaluated in terms of thermal comfort, indoor air quality, acceptability, availability period, comfort systems response time, comfort recovery as well as power and energy delivered. Both strategies were found to offer potential flexibility with significant reductions in peak power requirements over a maximum period of 120 minutes in the case of the fan experiment, and 20 mins in the case of the cooling temperature set-point experiment. Detailed results can be found in 40]. Additional work investigates the control of the air supply fan using PID-controlled duty cycles and the use of fixed cooling duty cycles, as well as explores some issues associated with localisation of changes to comfort parameters [41].

\section{Development of Monitoring Guidelines}

IEA EBC Annex 67 intends to provide guidance for those wishing to monitor buildings or sub-systems with a view to investigate the available energy flexibility. This guidance will be closely linked to issues identified in the various case studies and will also be linked to the key metrics and indicators of energy flexibility developed in Subtask A.

A special case of "user guidelines" is the collaboration with the "rules and regulations" definition of the Solar Decathlon Europe competition, which will be conducted in 2019 [42]. The idea is to focus on both energy load and generation profiles as well as interaction with the energy networks. The guidelines should lead to a more consistent judging on this topic, in terms of deliverables as well as during the testing period during the competition. This will enhance the dissemination of the results of IEA EBC Annex 67 to the younger generation.

\section{Investigation of Barriers and Motivations of Users}

Questionnaires have been developed by the Technical University of Eindhoven (NL) for both domestic and non-domestic occupants to assess the level of current knowledge of issues relating to Energy Flexibility and Smart Grids, and the perceived acceptability of various proposed interventions with regard to heating and ventilation controls, control of appliances, and changes in energy behaviours. The questionnaires were administered online to a large group of Dutch householders, receiving 785 effective responses [43]. The survey concluded that although there is a lack of knowledge about Smart Grid and Energy Flexibility, people are to some extent willing to become Energy Flexible. However, the awareness about Energy Flexibility needs to be increased and financial incentives are an important tool to increase the willingness to become Energy Flexible.

The office version of the questionnaire was also given to university building occupants in Eindhoven, Leeds Beckett (UK), EURAC (Italy) and University of Southern Denmark (USD). Work is underway to compare results from these different countries. Preliminary results show that there is a similar level of willingness in the 
Netherlands and the UK to engage in energy flexible behaviours despite the fact that a greater level of prior knowledge is reported by the respondents from the Netherlands.

\section{Dissemination}

The objective and the results of IEA EBC Annex 67 are already being disseminated via the website of the Annex (annex67.org) as well as through conference papers and articles in national and international journals. On www.annex67.org it is possible to subscribe to the IEA EBC Annex 67 Newsletter, which is published twice a year.

Furthermore, the dissemination will include a series of technical reports on specific topics. By the end of IEA EBC Annex 67, the aim is to prepare a source book summarizing the outcome of the Annex to a broader audience.

An important result from IEA EBC Annex 67 is a collection of example case studies, as it is easier for a larger community to understand Energy Flexibility when the definition and methodology are supported by well written examples showing how Energy Flexibility in buildings may be obtained and controlled. The goal is to select illustrative examples from different work packages within IEA EBC Annex 67, documented in a common format. The intention is to use these examples to extract some guidelines on how to optimize the available Energy Flexibility in buildings. It may especially be possible to recommend solutions and related control strategies.

\section{References}

[1] IEA PVPS. Snapshot of global PV markets 2014 - 2015.

[2] GWEC (Global Wind Energy Council). Global wind statistics 2014; 2015. http://www.gwec.net/wpcontent/uploads/2015/02/GWEC_GlobalWindStats2014_FINAL_10.2.2015.pdf.

[3] Directive 2009/28/EC of the European Parliament and of the Council of 23 April 2009 on the promotion of the use of energy from renewable sources and amending and subsequently repealing Directives 2001/77/EC and 2003/30/EC. OJ L 140, 5.6.2009, p. 16-62. http://data.europa.eu/eli/dir/2009/28/oj.

[4] The Federal Ministry for Economic Affairs and Energy (BMWi). The energy of the future: Fourth "energy transition” $\quad$ monitoring $\quad$ report $\quad-\quad$ summary. https://www.bmwi.de/BMWi/Redaktion/PDF/V/vierter-monitoring-bericht-energie-der-zukunft-englischekurzfassung,property=pdf, bereich=bmwi2012, sprache=de,rwb=true.pdf. 
[5] The Danish Government. The Danish climate policy plan: towards a low carbon society, 2013. https://stateofgreen.com/files/download/386.

[6] Hall, M. and Geissler, A. 2017. Different balancing methods for Net Zero Energy Buildings - Impact of time steps, grid interaction and weighting factors. CISBAT 2017 International Conference - Future Buildings \& Districts - Energy Efficiency from Nano to Urban Scale, CISBAT 2017 6-8 September 2017, Lausanne, Switzerland.

[7] Burger, B. and Hall, M., 2017. PVopti - hourly based energy balance for building design. CISBAT 2017 International Conference - Future Buildings \& Districts - Energy Efficiency from Nano to Urban Scale, CISBAT 2017 6-8 September 2017, Lausanne, Switzerland.

[8] H. Wirth, 2017. Recent Facts about Photovoltaics in Germany; Fraunhofer ISE, Freiburg. https://www.ise.fraunhofer.de/en/publications/veroeffentlichungen-pdf-dateien-en/studien-undkonzeptpapiere/recent-facts-about-photovoltaics-in-germany.pdf

[9] Van Roy, J. et al, 2016. Electric Vehicle Charging in an Office Building Microgrid With Distributed Energy Resources. IEEE Transactions on Sustainable Energy. Volume 5 Issue 4, 2016. http://ieeexplore.ieee.org/document/6810874/

[10] IEA, 2003. The Power to Choose - Demand Response in Liberalized Electivity Markets. OECD Publication, $\quad$ Paris. $\quad$ http://www.schneider-electric.us/documents/solutions1/demand-responsesolutions/powertochoose 2003.pdf.

[11] Roberta D'angiolella et al, 2016. NZEB 2.0: interactive players in an evolving energy system. REVHA Journal, vol. 53, issue 3, May 2016. http://www.rehva.eu/fileadmin/REHVA Journal/REHVA Journal_2016/RJ_issue 3/RJ1603 WEB.pdf

[12] De Grote, M., Volt, V. and Rapf, O., 2016. Smart Buildings in a Decarbonised Energy System. Building Performance Institute Europe. http://bpie.eu/publication/smart-buildings-in-a-decarbonised-energy-system/

[13] De Grote, M. et al, 2017. Is Europe Ready for the Smart Building Revolution? Building Performance Institute Europe. http://bpie.eu/publication/is-europe-ready-for-the-smart-buildings-revolution/

[14] EU, 2016. Proposal for an amending Directive on the Energy Performance of Buildings (draft). $\underline{\text { http://ec.europa.eu/energy/sites/ener/files/documents/1_en_act_part1_v16.pdf }}$

[15] EU, 2016. Impact Assessment on Proposal for an amending Directive on the Energy Performance of Buildings (draft). https://www.eumonitor.eu/9353000/1/j9vvik7m1c3gyxp/vk9u7weblow9 
[16] World Business Council for Sustainable Development (WBCSD), "Transforming the market: energy efficiency in buildings", 2009.

[17] Le Dréau, J. and Heiselberg, P., 2016. Energy flexibility of residential buildings using short term heat storage in the thermal mass. Energy, 111(8), 991-1002. http://doi.org/10.1016/j.energy.2016.05.076

[18] Reynders, G., Nuytten, T., and Saelens, D., 2013). Potential of structural thermal mass for demand-side management in dwellings. Building and Environment, 64, 187-199. http://doi.org/10.1016/j.buildenv.2013.03.010

[19] Patteeuw, D., Reynders, G., Bruninx, K., Protopapadaki, C., Delarue, E., D’haeseleer, W., and Helsen, L., 2015. CO2-abatement cost of residential heat pumps with active demand response: demand- and supplyside effects. Applied Energy, 156, 490-501. http://doi.org/10.1016/j.apenergy.2015.07.038 http://old.wbcsd.org/pages/edocument/edocumentdetails.aspx?id=11006\&nosearchcontextkey=true.

[20] Braun, J.E., 2003. Load control using building thermal mass. Transactions-American Society of Mechanical Engineers Journal of Solar Energy Engineering 125.3 (2003): 292-301.

[21] Braun, J.E., Montgomery, K.W. and Chaturvedi, N., 2001. Evaluating the performance of building thermal mass control strategies. HVAC\&R Research 7.4 (2001): 403-428.

[22] Morris, F.B., Braun, J.E. and Treado, S. J., 1994. Experimental and simulated performance of optimal control of building thermal storage." ASHRAE Transactions 100.1 (1994): 402-414.

[23] Finck, C., Li, R. and Zeiler, W. 2017. Performance maps for the control of thermal energy storage. BS 2017 IBPSA conference, San Francisco.

[24] K. Hedegaard et al. Wind power integration using individual heat pumps - Analysis of different heat storage options. Energy 47 pp 284-293, 2012. Elsevier. http://vbn.aau.dk/da/publications/wind-powerintegration-using-individual-heat-pumps--analysis-of-different-heat-storage-options(e34692df-b080-4c75a5ad-bdb1f2a4b26e).html

[25] Jensen, S.Ø. and Marszal-Pomianowska, A.J., 2016. IEA EBC Annex 67 Energy Flexible Buildings. Proceedings of the CLIMATE 2016 conference, Aalborg, Denmark. http://vbn.aau.dk/da/publications/iea$\underline{\text { ebc-annex-67-energy-flexible-buildings(dfafe56e-e500-4d1e-87cc-36cdf6068eeb).html }}$

[26] Jensen, S.Ø., Christensen, C.H., Jørgensen, D.M. and Huet, J., 2016. Smart Meter Case Study. Danish Technological Institute. Report part of the iPower Project - www.ipower-net.dk.

[27] Dufour, 2013. Define Interface Between VPP and Powerplant (Case Study). Greenwave Systems. Report part of the iPower Project - www.ipower-net.dk. 
[28] Stinner, S., Huchtemann, K. and Müller, D., 2016. Quantifying the Operational Flexibility of Building Energy Systems with Thermal Energy Storage. Applied Energy, vol. 181, pp. 140-154. http://ac.elscdn.com/S0306261916311424/1-s2.0-S0306261916311424-main.pdf? tid=5ccdb24c-dbe0-11e6-9d4700000aacb360\&acdnat $=1484566915$ 0bc1345606b08e882243c34cabad444b.

[29] Jensen, S.Ø., 2015. IEA EBC Annex 67 Energy Flexible Buildings - Annex Text. www.annex67.org.

[30] Lopes, R.A., Chambel, A., Neves, J., Alenei, D., Martins, J. A literature review of methodologies used to assess the energy flexibility of buildings. Energy Procedia, 91 (2016) 1053-1058. http://www.sciencedirect.com/science/article/pii/S1876610216303745

[31] Marszal-Pomianowska, A., Reynders, G., Lopes, R.A. and Aelenei, D., 2017. Energy Flexible Buildings: A review of definitions and quantification methodologies. Submitted to Energy and Buildings

[32] Klein, K., Herkel, S., Nenning, H. and Felsmann C., 2017. Load shifting using the heating and cooling system of an office building: Quantitative potential evaluation for different flexibility and storage options. Applied Energy $203 \quad$ (2017) 917-937. http://ac.els-cdn.com/S0306261917308231/1-s2.0$\underline{\text { S0306261917308231-main.pdf? tid=8ff7f952-6aba-11e7-82d2- }}$

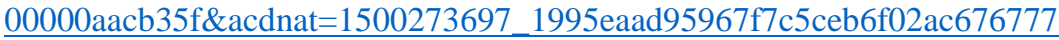

[33] I. Gaetani, I., Hoes, P.-J. and Hensen. J.L.M., 2016. Occupant behaviour in building energy simulation: Towards a fit-for-purpose modelling strategy, Energy \& Buildings 121 (2016), 188-204. https://www.researchgate.net/publication/298796959_Occupant behavior_in_building_energy_simulation Towards_a fit-for-purpose_modeling_strategy

[34] Investigating the potential evolution of the EU Target Model necessary to secure the European power system decarbonisation with large amounts of renewables - Market4RES, http://market4res.eu/

[35] Klein, K., Killinger, S., Fischer, D., Streuling, C., Salom, J. and Cubi, E., 2016. Comparison of the Future Residual Load in Fifteen Countries and Requirements to Grid-Supportive Building Operation. EuroSun 2016. http://www.uibcongres.org/eurosun/ponencia.en.html?mes=120\&ordpon=1

[36] Clauß, J., Finck, C., Vogler-Finck, P. and Beagon, P., 2017 Control strategies for building energy systems to unlock demand side flexibility - A review; conference paper, IPBSA Building Simulation 2017, San Francisco

[37] Stafford A., 2017. An Exploration of Load-shifting Potential in real in-situ Heat-Pump/Gas-Boiler Hybrid Systems. Building Services Engineering Research \& Technology. (in press)

[38] The HPCOM project. www.hpcom.dk. 
[39] Ionesi, A., Jradi, M., Kjærgaard, M.B. and Veje, C., 2015. Towards seamless integration of model-based performance simulation and multi-objective optimization tools. Proceedings of 14th Conference of International Building Performance Simulation Association, Hyderabad, India, December 7-9, 2015. http://www.ibpsa.org/proceedings/BS2015/p2824.pdf

[40] Aduda, K.O., Labeodan, T., Zeiler, W., Boxem, G. and Zhao, Y., 2016. Demand side flexibility: Potentials and building performance implications. Sustainable Cities and Society, vol 22, pp 146-163. https://www.infona.pl/resource/bwmeta1.element.elsevier-4eb0617f-f79f-3987-ab2e-33360ef9c034

[41] Aduda, K.O., Labeodan, T., Zeiler, W. and Boxem, G., 2017. Demand-side flexibility co-ordination in office buildings: A framework and case study application. Sustainable Cities and Society, vol. 29, pp 139158. https://pure.tue.nl/ws/files/53357624/pagination_SCS_551.pdf

[42] Solar Decathlon Europe, http://solardecathlon.eu/

[43] Li, R., Dane, G., Finck, C. and Zeiler, W. 2017. Are building users prepared for energy flexible buildings? A large-scale survey in the Netherlands. Submitted to Applied Energy. 